\title{
MAPPING OF THE MICRORELIEF STRUCTURES USING TOPOGRAPHIC DATA
}

DOI: https://doi.org/10.18509/AGB.2018.03

UDK: 528.93.06(470)

\author{
Evgeny Panidi ${ }^{1}$, Lubov Trofimetz ${ }^{2}$, Julia Sokolova $^{1}$, Elena Kunaeva $^{1,3}$ \\ ${ }^{1}$ Saint Petersburg State University, Russia; ${ }^{2}$ Orel State University, Russia \\ ${ }^{3}$ Pushkin Leningrad State University, Russia \\ Corresponding author: panidi@ya.ru,e.panidi@spbu.ru
}

Submitted: January 2017, Accepted: May 2017, Published: October 2017

\begin{abstract}
The paper describes case study, which we conducted using test area located in Central European Russia (Orel region, Suhaya Orlitsa river basin). The archived topographic (cartographic) data, data of topographic survey and satellite imagery were used as study materials. We have estimated the accuracies and limits of microrelief interpretation basing on the cartographic and survey materials. Derivative geomorphometric maps were used as enabling tool for interpretation of the microrelief strictures. Very high resolution space satellite imagery were used as reference data.
\end{abstract}

Key words: Microrelief Mapping, Accuracy Estimation, Geomorphometry, Very High Resolution Space Satellite Imagery

\section{Introduction}

Our study is devoted to the investigation of techniques applicable for mapping microrelief structures (structures with the transverse size up to the first tens of meters), which are most hardly interpretable and most changeable in time/space. Microrelief mapping is demanded in such domains as precision agriculture, melioration and recultivation, ecological hazard assessment, etc. However, the task of interpretation of the microrelief structures remains time consuming and difficult for automation.

Direct allocation and survey of such small landforms is effective but inconvenient on large areas. Remote sensing techniques and data (e.g., very high resolution satellite imagery, aerial photography, laser scanning) being highly automated remains hardly suitable for vegetated areas. Also, the general purpose large-scale topographic data (topographic maps and survey materials) being unspecialized microrelief data sources produce some specific interpretation errors and need to be processed and utilized correctly. In this paper, we describe some results of erosional structures interpretation and mapping using topographic (cartographic) data and topographic survey.

This case study was produced on the test area (Fig. 1) which is located in Orel region (central part of European Russia), in the Suhaya Orlitsa river basin (approximate coordinates are $35^{\circ} 57^{\prime} 35.10^{\prime \prime}$ of East longitude and $53^{\circ} 02.33^{\prime \prime}$ of North latitude). The test area is covered by cultivated (arable) lands, and can be characterized as the territory with high risks of erosion. Microrelief at the area is composed mainly of hills divided by erosional ravines.

This case study is a part of study series concerned with investigation of dependencies between quantitative (geomorphometric) parameters of microrelief, soil runoff and migration of soil pollutants [7], [9]. 




Figure 1: Satellite image of the test area collected on May 19, 2012, image courtesy of the DigitalGlobe Foundation

\section{Used approach and data}

Most models of soil runoff and redistribution use relief data to estimate impact of erosional network [7], [8], [9]. At the microrelief scale, erosional network is composed of ancient ravines (eroded landforms, which are easily interpreted on maps) and modern streams (young erosional landforms, which are hard for interpretation because of absence of the eroded ravine) [7], [9]. While modern streams produce significant erosional impact [9], the issue of interpretation of these erosional structures has great value when modeling at large scale.
In many cases, ancient ravines appear "continued" by modern streams in upper parts (Fig. 2). These upper parts are hardly interpretable on topographic maps of 1:10000 scale, which are widely used in land management. The catchment area [1] maps are used to estimate locations of modern streams. However, modern streams are not coincide with the thalwegs of ancient ravines in many cases. It leads to the incorrect representation of the streams on catchment area maps at large scale, which is amplified by the errors in relief representation on initial topographic maps. 


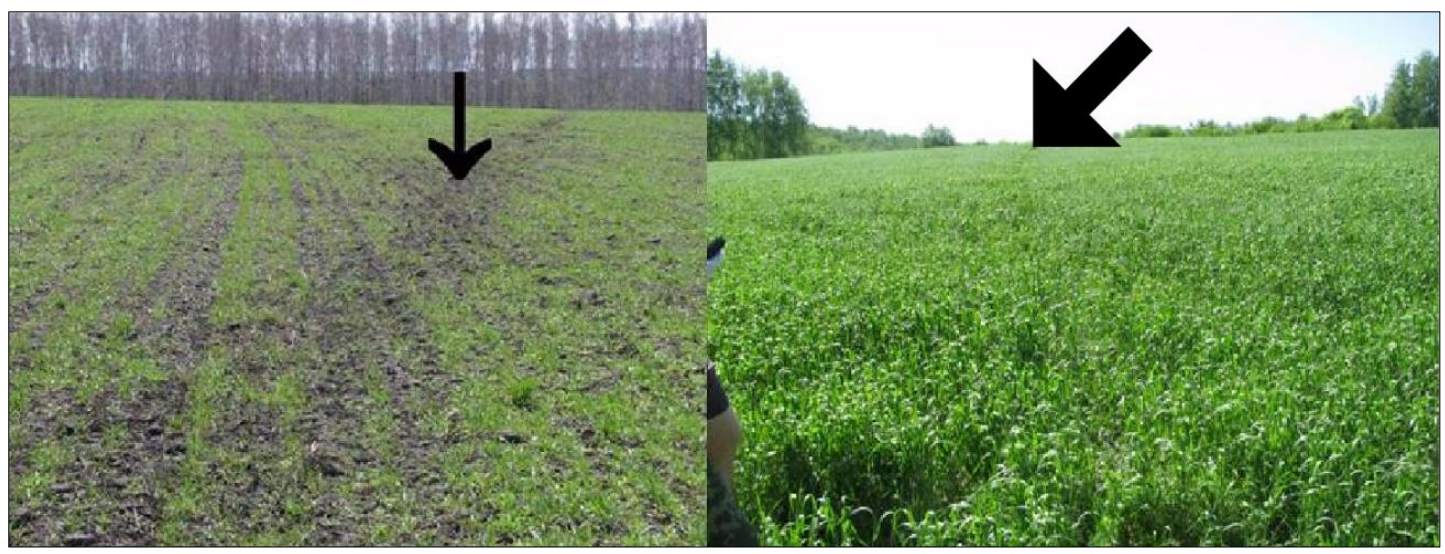

Figure 2: Modern stream can be allocated visually in different seasons, in the autumn (left image) and in the summer (right image) during the active vegetation growth

All mentioned features lead to the need of ground control and estimation of correctness and accuracy of the erosional network representation on large-scale catchment area maps. Such a ground control can be provided through the field survey or through the use of highly detailed remote sensing data (aerial photography or satellite imagery). Also, the comparison of topographic data produced at different scales can be helpful for estimation of scale impact onto the completeness of erosional network interpretation.

Initial Data: We used two topographic datasets to estimate interpretability of the modern streams and its relative accuracy. The first dataset is the topographic map of 1:10000 scale, and the second is the topographic survey data of 1:500 scale. Both datasets were used to extract Digital Elevation Models (DEMs) and to produce derivative geomorphometric maps (namely, catchment area maps are discussed in this paper). Additionally, we apply the WorldView-1 very high resolution (0.5 $\mathrm{m} /$ pix) satellite image of our test area (Fig. 1) as a referential dataset, to ensure visual interpretation and verification of the modern stream positions. As we recognized before, very high resolution satellite imagery collected in the spring (before the active vegetation growth) can show clearly the erosional network composed of modern streams [5], [6].

Software: We used the ESRI ArcGIS and SAGA software. The ArcGIS was used mostly as the data preparation and data aggregation tool, DEMs were extracted in
ArcGIS also. SAGA was used to extract geomorphometric maps.

DEM extraction parameters. As the test area has the hilly plain relief, the Spline tool was applied to interpolate DEMs in ArcGIS, despite the presence more complex Topo to Raster tool that needs more parametrization for correct modeling [3]. The tool was parametrized to use spline with tension [4] in the computations, and the weight parameter was appointed as 0 to ensure Thin Plate Spline interpolation [2].

Catchment area maps extraction: The DEMON algorithm [1] was used to produce catchment area maps from the DEM data in SAGA.

Interpretation techniques: We used manual (visual) technique to interpret erosional microrelief structures. The interpretation was conducted separately using $1: 10000$ topography data, $1: 10000$ and 1:500 catchment area maps, and satellite image. This technique made it possible to provide comparative estimation of erosional structures interpretability.

\section{Results}

Comparison of used datasets show clearly that use of topographic map contours at different scales and satellite image produce different results of visual interpretation of the streams (streamlines) (Fig. 3). Topographic contours itself allow to interpret only main streamlines with great loss in lengths and catchment areas (Table 1). Loss in catchment area estimation based on the topographic contours (that is a clas- 
sic approach) will produce compatible great loss in consequential estimation of the soil runoff. The values in Table 1 were computed for the slope presented on Figure 3 and for the neighboring parts of the same slope.

It is notable also, that both 1:10000 and 1:500 scale maps have similar contour patterns that do not reflect details of erosional network (Fig. 3b) and do not coincide ex-



Figure 3: Streams on the arable slope, image courtesy of the DigitalGlobe Foundation (a); DEM produced from topographic survey using regularized spline function (b); for both images: red points measurements of topographic survey at 1:500 scale, brown lines - contours of the 1:10000 scale topographic map

Table 1: Lengths and catchment areas of the streams estimated using contours of the 1:10000 scale topographic map and derived catchment area map

\begin{tabular}{|c|c|c|c|c|c|}
\hline 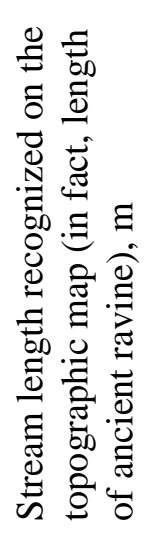 & 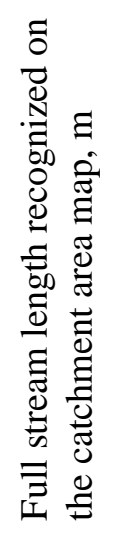 & 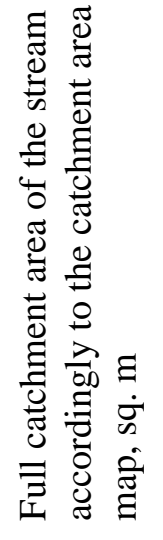 & 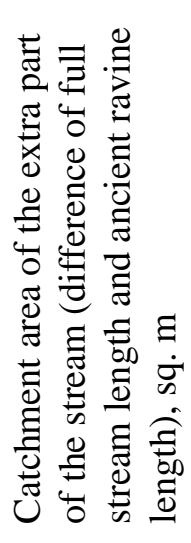 & 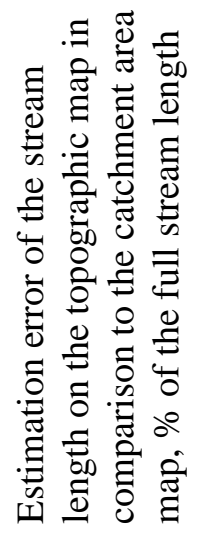 & 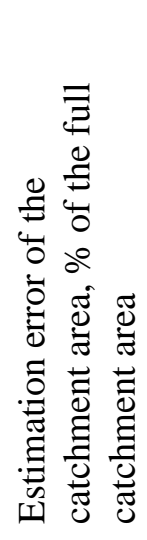 \\
\hline 153 & 298 & 4125 & 2700 & 49 & 65 \\
\hline 244 & 352 & 33471 & 1688 & 31 & 5 \\
\hline 167 & 300 & 4138 & 2500 & 44 & 60 \\
\hline 284 & 334 & 47557 & 4180 & 15 & 9 \\
\hline 107 & 309 & 5588 & 3087 & 65 & 55 \\
\hline 119 & 329 & 7583 & 1936 & 54 & 26 \\
\hline 196 & 283 & 7063 & 795 & 31 & 11 \\
\hline
\end{tabular}


Comparison of the real positions of the streams derived from satellite image (Fig. 4) with positions derived from catchment area maps of 1:10000 and 1:500 scale (Fig. 4c and 4d) show that catchment area maps produce well estimation of the stream lengths. The lengths of the main (longest) streamlines of tree-type streams in western and eastern parts of test area differ in 2 and $12 \%$ accordingly with lengths derived from 1:10000 catchment area map, and in 3 and $11 \%$ with lengths derived from 1:500 catchment area map.
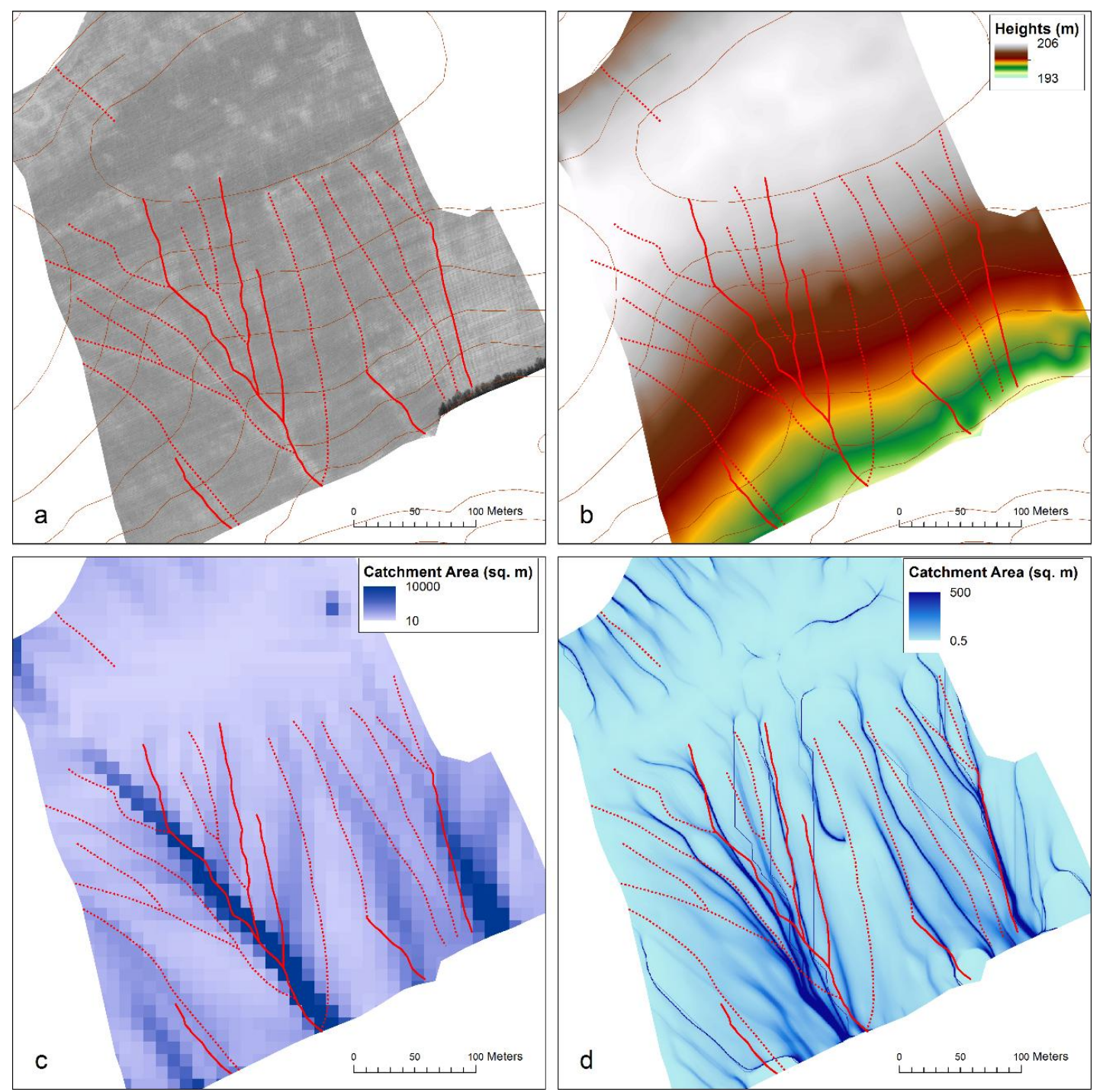

Figure 4: Positions of modern streams interpreted on the satellite image directly as stream bodies (red lines) and indirectly as flushed (light) lines on the image (dotted red lines); streams overlaid with satellite image (a), DEM of 1:500 scale (b), catchment area map of 1:10000 scale (c) and catchment area map of 1:500 scale (d); brown lines on the images a and b are the contours of the 1:10000 scale topographic map
It is notable also that catchment area maps show almost equal estimations of main streamlines, while map of 1:10000 scale show only main streamlines and the map of 1:500 scale gives higher detailing of tree-type streams structure and higher detailing of catchment area values distribution. It is valuable that produced maps show correct representation of main streamlines on the map of 1:10000 scale. 
Another one notable feature is the differences in real positions of the streams and positions estimated basing on map of larger (1:500) scale. These differences are explained by the nature of modern streams, which take position depending not only of ancient relief structures, but also in correspondence with cover of slope surface. In case of arable areas, even the direction of the ploughing and presence of agricultural machinery tracks can be valuable factors of stream pattern formation. Therefore, mapping of the streamlines in higher scales can be recognized only as approximation, while the real positions of the streams will differ from the mapped positions.

Finally, despite the smoothness of the relief surface presented on the topographic maps of test area (i.e., inability of interpretation of the secondary streams and higher parts of main streams), the derivative catchment area maps give correct estimation of stream lengths and correct picture of overall structure of the modern stream network. Higher scale of the map produces highly detailed structure.

\section{Conclusions}

Our investigations showed that classic approach to the allocation of stream lengths basing on the contours of topographic map produce loss in the length estimation up to the $50 \%$ and more. On the other hand, the catchment area maps derived from the same topographic data allow to estimate stream lengths with higher accuracy, and to interpret structure of streams. It makes possible to use catchment area maps for typification of the modern streams.

Catchment area maps produced from topographic maps of 1:10000 and 1:500 can allow compatible accuracy when estimating stream lengths of main streams that correspond with the ancient ravines. Due to this, the catchment area maps of 1:500 1:10000 scales can be used for accurate measurement of stream lengths (however, more statistics are needed to prove this preliminary conclusion).

\section{Acknowledgements}

The study was partially supported by Russian Foundation for Basic Research (RFBR) research project No. 15-05-07463 A. Used Space Satellite Imagery is Courtesy of the DigitalGlobe Foundation.

\section{References}

[1] Costa-Cabral M.C., Burges S.J. Digital Elevation Model Networks (DEMON): A model of flow over hillslopes for computation of contributing and dispersal areas. Water Resources Research, Vol. 30, Issue 6, pp. 1681-1692, 1994. doi:10.1029/93WR03512

[2] Duchon J. Interpolation des fonctions de deux variables suivant le principe de la flexion des plaques minces. Revue Française d'Automatique, Informatique et Recherche Opérationnelle. Analyse numérique, Vol. 10, n² 2, p. 5-12, 1976 (in French)

[3] Hutchinson M.F., Xu T. Stein J.A. Recent Progress in the ANUDEM Elevation Gridding Procedure. In: Hengel T., Evans I.S., Wilson J.P., Gould M. (eds.) Geomorphometry, Redlands, California, USA, pp. 19-22, 2011. Accessible at: http://geomorphometry.org/HutchinsonXu2011

[4] Mitáš L., Mitášová H. General variational approach to the interpolation problem. Computers \& Mathematics with Applications, Vol. 16, Issue 12, pp. 983-992, 1988. doi:10.1016/0898-1221(88)90255-6

[5] Panidi E., Sokolova J., Trofimetz L., Kunaeva E. Mapping of the microrelief structures using multitemporal very high resolution space imagery. Acta Geobalcanica , Vol. 2, Issue 2, pp. 103-109, 2016. doi:10.18509/AGB.2016.11 
[6] Panidi E., Sokolova J., Trofimetz L., Kunaeva E. Satellite imagery applied to mapping of the erosion microrelief structures. SGEM2016 Conference Proceedings, Book 2, Vol. 3, pp. 415-422, 2016. doi:10.5593/SGEM2016/B23/S11.053

[7] Panidi E., Trofimetz L., Sokolova J. Application of phyto-indication and radiocesium indicative methods for microrelief mapping. IOP Conference Series: Earth and Environmental Science, Vol. 34, Paper ID: 012024, 6 p., 2016. doi:10.1088/1755$1315 / 34 / 1 / 012024$

[8] Saavedra C., Mannaerts C.M. Erosion estimation in an Andean catchment combining coarse and fine resolution satellite imagery. Proceedings of the 31st International Symposium on Remote Sensing of Environment, paper 1017, 4 p. Accessible at: http://www.isprs.org/proceedings/2005/isrse/html/papers/1017.pdf

[9] Trofimets L.N., Panidi E.A. Study of soil loss quantity on the arable territories using estimations of soil pollutants migration and geomorphometric parameters of the microrelief. SGEM2015 Conference Proceedings, Book 3, Vol. 2, pp. 341-348, 2015. doi:10.5593/SGEM2015/B32/S13.046 